\title{
EFICÁCIA DE AÇÃO EDUCATIVA COM REEDUCANDDAS DE CADEIA PÚBLICA DE MATO GROSSO SOBRE O VÍRUS HPV
}

\section{Paula Kathleen Demétrio Corsino}

Enfermeira graduada pela Universidade do Estado de Mato Grosso, câmpus de Tangará da Serra (MT), Brasil.

\section{Vagner Ferreira do Nascimento}

Doutor em Bioética. Docente Adjunto Curso de Enfermagem Universidade do Estado de Mato Grosso, câmpus de Tangará da Serra (MT), Brasil.

\section{Grasiele Cristina Lucieto}

Docente assistente, curso de Enfermagem da Universidade do Estado de Mato Grosso, câmpus de Tangará

\section{Thalise Yuri Hattori}

Docente assistente, curso de Enfermagem da Universidade do Estado de Mato Grosso, câmpus de TTangará da Serra (MT), Brasil.

\section{Bianca Carvalho da Graça}

Acadêmica de Enfermaga da Universidade do Estado de Mato Grosso, câmpus de Tangará da Serra (MT), Brasil. Bolsista (PIBIC).

\section{Mariano Martinez Espinosa}

Docente associado da Universidade Federal de Mato Grosso, departamento de Estatística, Brasil.

\section{Ana Cláudia Pereira Terças-Trettel}

Doutora em Medicina Tropical IOC/FIOCRUZ. Docente Adjunta Curso de Enfermagem Universidade do Estado de Mato Grosso, câmpus de Tangará da Serra (MT), Brasil. da Serra (MT), Brasil.

RESUMO: O humano papiloma vírus impacta diretamente na mortalidade das mulheres quando associado ao câncer de colo uterino. Objetivou-se analisar o impacto de ação educativa realizada com reeducandas de Cadeia Pública Feminina de Mato Grosso. Trata-se de um estudo quantitativo, experimental e comparativo inferencial do tipo "antes e depois" conduzido com totalidade das mulheres. A análise estatística utilizou o teste McNemar, sendo significativos aqueles resultados com $p$ valor $<0,005$. Houve um implemento significativo no conhecimento dessas mulheres, principalmente em relação ao acesso à informação na prisão, transmissão pelo beijo, sexo oral e compartilhamento de roupas íntimas, cura espontânea, existência de cura. Além da relação desse vírus com verrugas genitais, e outras doenças associadas $(p<0,001)$. Percebe-se claramente que ações educativas são formas eficientes de informação e que instrumentalizam as mulheres na tomada de decisão, sendo primordiais na redução das vulnerabilidades e potencializando a melhoria de sua qualidade de vida.

PALAVRAS-CHAVE: Conhecimento; HPV; Saúde da mulher.

\section{EFFICACIOUSNESS OF EDUCATIONAL ACTIVITIES ON HPV WITH DETAINEES IN MATO GROSSO, BRAZIL}

ABSTRACT: Human Papilloma Virus impacts directly on female mortality when associated with cervical cancer. Current analysis deals with the impact of educational tasks with detainees in a Female Public Prison in Mato Grosso, Brazil. Current quantitative, experimental and comparative study, before-and-after type, was conducted exclusively with females. McNemar Test was employed for statistical analysis with $p<0.005$ significance. The detainees' information was upgraded, especially with regard to transmission by kisses, oral sex, sharing of underwear, spontaneous cure and the existence of a cure, relationship of the virus with genital warts, and to other associated diseases $(p<0.001)$. It may be perceived that educational tasks are efficient forms in providing information and help females in decision-taking, reducing vulnerable conditions and empowering improvement in life quality.

KEY WORDS: Knowledge ; Papillomaviridae ; Women's Health.

\section{INTRODUÇÃO}

Autor correspondente:

Ana Cláudia Pereira Terças-Trettel

E-mail: enfanacnp@gmail.com
O papiloma vírus humano, conhecido como HPV (Human papiloma virus), pertence à família do Papivaviridae e é responsável por doenças causadas pelo contato sexual desprotegido.1 Há mais de 150 
tipos do vírus HPV, dentre eles cerca de 40 já foram isolados do epitélio da mucosa genital. No entanto, 12 possuem potencial oncogênico, com destaque para o HPV 16 e 18 , que estão presentes em cerca de $70 \%$ dos casos de cânceres cervicais, $50 \%$ das lesões pré-cancerosas de alto risco e $25 \%$ das lesões de baixo risco. Em contraponto, contudo, os vírus 6 e 11, de baixo risco para câncer, estão relacionados com $90 \%$ dos casos de condiloma acumina$\mathrm{do}^{1,2}$.

O panorama mundial de infecção por HPV é de 600 milhões de pessoas, sendo que $75 \%$ a $80 \%$ dessa população adquirem mais de uma cepa do vírus. Anualmente, cerca de $15 \%$ das mulheres que ainda não entraram em contato com vírus serão infectadas pelo HPV, sendo 25\% dessas na faixa etária de 15 a 19 anos. Acredita-se que 10 milhões de pessoas no Brasil podem ser portadoras do vírus, principalmente a população jovem, tornando o Brasil um dos líderes mundiais de infecção pelo vírus HPV, com registro anual de 700 mil novos casos ${ }^{3}$.

Como citado anteriormente, a relação entre o HPV e o câncer de colo uterino vem preocupando a comunidade científica, visto que apresenta um lugar de destaque nas taxas de mortalidade entre a população feminina. Todos os anos, 500 mil mulheres são diagnosticadas com câncer de colo uterino e 270 mil morrem por causa da doença. ${ }^{1}$ As altas taxas de incidência, nos países subdesenvolvidos e em desenvolvimento, podem relacionar-se com o perfil epidemiológico dessas mulheres, os fatores de risco e as ações em todos os níveis de atenção à saúdé .

Sabe-se que as vulnerabilidades em saúde contribuem para o desenvolvimento de doenças infecciosas, assim as mulheres em situação de prisão constituem um grupo de risco ampliado.

$\mathrm{O}$ número de mulheres encarceradas vem aumentando anualmente. De acordo com o Ministério de Justiça, a taxa de encarceramento aumentou $66 \%$ entre 2004 e $2014^{5}$.

Esse cenário vem preocupando os órgãos responsáveis pela saúde da mulher encarcerada, pois a superlotação aumenta as chances de adoecimento, em especial por infecções sexualmente transmissíveis(IST). O direito à saúde dessa população é fundamentado e legitimado pelo Plano Nacional de Saúde do Sistema Peni- tenciário, porém as prisões não possuem infraestrutura adequada para o cuidado dessas mulheres ${ }^{6}$.

A saúde dessas mulheres é pouco discutida, mesmo possuindo amplo arcabouço legal como a Política Nacional de Atenção Integral à Saúde da Mulher e no Plano Nacional de Saúde no Sistema Penitenciário (PNSSP) 5 . Em atenção às referidas legislações, torna-se então primordial a realização de estudos que abordem a saúde das mulheres com privação de liberdade, com intuito de reduzir as iniquidades a que estão sujeitas e promover a qualidade de vida.

Vislumbrando esse cenário social, este estudo tem por objetivo analisar o impacto de ação educativa sobre HPV realizada com mulheres em situação de prisão em Mato Grosso.

\section{METODOLOGIA}

Trata-se de um estudo experimental, comparativo inferencial do tipo "antes e depois", o qual envolve a observação da variável dependente em dois períodos de tempo, antes e após a administração do tratamento experimental, estratégia similar à utilizada por Luchesi; Santos ${ }^{7}$.

A pesquisa foi realizada em uma cadeia pública feminina com a população de 53 mulheres reeducandas privadas de liberdade, no município de Tangará da Serra, localizado na região Sudoeste do Estado de Mato Grosso, a $240 \mathrm{~km}$ da capital, Cuiabá 8 .

Foram incluídas no estudo 53 reeducandas, que representam todo o universo populacional de mulheres aprisionadas na cadeia pública feminina do município polo do médio norte de Mato Grosso, presentes no período da coleta de dados em outubro de 2016.

Os critérios de inclusão foram as mulheres que se encontravam privadas de liberdade na cadeia pública feminina dessa localidade, tanto as condenadas quanto as que estavam em regime provisório de detenção. Os critérios de exclusão foram aplicados para aquelas que verbalizaram a desistência da participação no estudo ou cansaço físico \mental.

A coleta de dados foi realizada em outubro de 2016 e composta por dois momentos distintos, primeira- 
mente foi explicado às mulheres sobre o teor da pesquisa; aplicado um questionário acompanhado pelas pesquisadoras, assim as reeducandas da cadeia o responderam individualmente, expressando seus conhecimentos prévios sobre o vírus HPV. Em seguida, foi realizada uma ação educativa sobre o tema com duração de 30 minutos, o método de troca de conhecimentos se deu por atividade expositiva, utilizando cartazes com imagens relacionado ao HPV, modo de transmissão, diagnóstico, tratamento e prevenção, sendo então possibilitado o momento reflexivo com as discussões e respostas aos questionamentos feitos pelas reeducandas. Visando reduzir o viés de coleta foram discutidos diferentes aspectos do tema e não apenas as resposta do questionário.

Após sete dias aplicou-se o mesmo questionário que precedeu a ação educativa. A ação foi desenvolvida em uma sala de aula da instituição prisional. O instrumento de coleta de dados foi elaborado pelos autores e estruturado no formato de questionário com perguntas objetivas idênticas no pré e pós-teste.

Os dados foram digitalizados em planilhas eletrônicas, estes então foram importados para o SPSS (Statistical Package for the Social Sciences), versão 20.0 e constituíram o banco de dados. Para as análises estatísticas foram pareados os questionários antes e depois, organizados nas seguintes categorias: (I) corretas no préteste e que permaneceram corretas pós-teste, (II) corretas antes e erradas após a intervenção, (III) erradas no pré-teste e corretas no pós-teste e (IV) erradas antes da intervenção e que permaneceram erradas.

Foi utilizado o teste estatístico não paramétrico denominado Teste Binomial nas duas análises, sendo que na análise do pós-teste, ele foi utilizado como uma simplificação do teste de McNemar para significância das mudanças. ${ }^{9} \mathrm{O}$ teste de McNemar é aplicável a situações do tipo "antes e depois" em que cada indivíduo é observado duas vezes: antes e depois de certo tratamento e desejase testar a sua eficiência. Cada indivíduo se encaixa em uma das categorias de resposta, antes e depois do tratamento. Este teste avalia se as mudanças de uma categoria para outra são significativas, assim foram considerados significantes aqueles resultados com $\mathrm{p}$ valor menor ou igual a 0,05 e intervalo de confiança de $95 \%$.

O estudo foi aprovado pelo Comitê de Ética em
Pesquisa com Seres Humanos da Universidade do Estado de Mato Grosso, sob CAAE: 50417815.8.0000.5166 e parecer 1.457.621 $\backslash 2016$. Todas as mulheres que aceitaram participar da pesquisa assinaram o Termo de Consentimento Livre e Esclarecido (TCLE), tal como recomenda a resolução 466/2012; a assinatura do TCLE foi realizada na semana anterior à pesquisa, em entrevistas individuais.

\section{RESULTADOS}

O perfil das 53 mulheres em situação de prisão que participaram do estudo possui, em sua maioria, jovens com idade que varia de 18 e 59 anos, média 31,6 anos, e a faixa etária mais prevalente entre 18 a 31 anos (55\%). A raça/cor dominante foi a parda $(73,2 \%)$, grau de escolaridade que predominou foi o ensino fundamental ultrapassando $50 \%$ das entrevistadas e somente $5 \%$ das reclusas possuem ensino superior.

A maior parcela de reeducandas é solteira (48\%), e possuem filhos, sendo que $60,3 \%$ possuem até três filhos, dentre as profissões referidas pelas reclusas, estão ser do lar $(38,2 \%)$ e vendedora $(9,1 \%)$. As causas da reclusão mais incidentes foram o tráfico de drogas (55\%), seguido por homicídio $(12,7 \%)$ e roubo (10,9\%), e o tempo de detenção mais identificado foi de até dois anos $(82,9 \%)$, sendo que a maioria $(61,1 \%)$ foi detida pela primeira vez.

Estas mulheres expressaram a necessidade de ter acesso a informações sobre como melhorar sua saúde, e que em relação ao conhecimento sobre o HPV, apenas $26,4 \%$ tiveram acesso a algum tipo de informação fornecida por profissional de saúde anterior à detenção e nenhum contato com informação sobre saúde após o encarceramento.

Os locais que mais colaboraram com o conhecimento das reeducandas sobre o HPV, antes da ação educativa realizada neste estudo, foram a escola e a comunicação em mídia e redes sociais, no entanto a ação educativa realizada na prisão foi importante fonte de acesso ao conhecimento em saúde (Tabela 1). 
Tabela 1. Local onde adquiriu conhecimento sobre HPV antes e após ação educativa realizada na Cadeia Pública Feminina e teste de McNemar, com suas respectivas diferenças ( $\Delta$ ), intervalo de confiança de 95\% (IC95\%) e valores de $p$, Tangará da Serra - MT, 2016

\begin{tabular}{|c|c|c|c|c|c|c|c|}
\hline \multirow{2}{*}{ Variável } & \multirow{2}{*}{ Pré } & Pós & & \multirow{2}{*}{ Total } & \multirow{2}{*}{$\Delta$} & \multirow{2}{*}{ IC95\% } & \multirow{2}{*}{$P$} \\
\hline & & Sim & Não & & & & \\
\hline \multirow[t]{3}{*}{ Em casa } & Sim & 2 & 5 & 7 & 0,0270 & $(-0,1587 ; 0,2127)$ & 1,000 \\
\hline & Não & 4 & 26 & 30 & - & - & - \\
\hline & Total & 6 & 31 & 37 & - & - & - \\
\hline \multirow[t]{3}{*}{ Na escola } & Sim & 5 & 3 & 8 & $-0,1351$ & $(-0,3324 ; 0,0621)$ & 0,227 \\
\hline & Não & 8 & 21 & 29 & - & - & - \\
\hline & Total & 13 & 24 & 37 & - & - & - \\
\hline \multirow[t]{3}{*}{ Na ESF } & Sim & 1 & 4 & 5 & $-0,0811$ & $(-0,2818 ; 0,1197)$ & 0,549 \\
\hline & Não & 7 & 25 & 32 & - & - & - \\
\hline & Total & 8 & 29 & 37 & - & - & - \\
\hline \multirow{3}{*}{$\begin{array}{l}\text { Comunicação em mídia } \\
\text { e redes sociais }\end{array}$} & Sim & 5 & 12 & 17 & 0,2160 & $(-0,0110 ; 0,4430)$ & 0,077 \\
\hline & Não & 4 & 16 & 20 & - & - & - \\
\hline & Total & 9 & 28 & 37 & - & - & - \\
\hline \multirow[t]{3}{*}{ Na cadeia } & Sim & 2 & 1 & 3 & $-0,5776$ & $(-0,7709 ;-0,3642)$ & $<0,001$ \\
\hline & Não & 22 & 12 & 34 & - & - & - \\
\hline & & 24 & 13 & 37 & - & - & . \\
\hline
\end{tabular}

*: observações não são discrepantes.

No presente estudo, a realização da ação educativa contribuiu significativamente com a informação dessas mulheres sobre o HPV, uma vez que apresentou significância estatística (Tabela 1).

O modo de transmissão do HPV foi uma das variáveis mais alteradas por essa ação educativa, ou seja, a informação foi significativa para o aprendizado das reeducandas, pois a via de transmissão conhecida previamente por essas mulheres era exclusivamente a via sexual, vaginal e anal. Após a ação educativa, a informação sobre a transmissão pelo sexo oral e pelo partilhamento de roupas íntimas e toalhas sem higienização prévia foram destacadas, além da desmistificação da transmissão pelo beijo em situações de lesões específicas (Tabela 2). 
Tabela 2. Conhecimento sobre modo de transmissão do HPV antes e após ação educativa realizada na Cadeia Pública Feminina e teste de McNemar, com suas respectivas diferenças $(\Delta)$, intervalo de confiança de $95 \%$ (IC95\%) e valores de $p$, Tangará da Serra, MT, 2016

\begin{tabular}{|c|c|c|c|c|c|c|c|}
\hline \multirow{2}{*}{ Variável } & \multirow{2}{*}{ Pré } & Pós & & \multirow{2}{*}{ Total } & \multirow{2}{*}{$\Delta$} & \multirow{2}{*}{ IC95\% } & \multirow{2}{*}{$P$} \\
\hline & & Sim & Não & & & & \\
\hline \multirow{3}{*}{ Pelo beijo } & Sim & 7 & 2 & 7 & $-0,5581$ & $(-0,7556 ;-0,3607)$ & $<0,001$ \\
\hline & Não & 26 & 8 & 30 & - & - & - \\
\hline & Total & 33 & 10 & 37 & - & - & - \\
\hline \multirow{3}{*}{$\begin{array}{c}\text { Através do sexo vaginal } \\
\text { e anal }\end{array}$} & Sim & 36 & 0 & 36 & $*$ & $*$ & * \\
\hline & Não & 0 & 7 & 7 & - & - & - \\
\hline & Total & 36 & 7 & 43 & - & - & - \\
\hline \multirow{3}{*}{ Pelo sexo oral } & Sim & 13 & 3 & 16 & $-0,4186$ & $(-0,6268 ;-0,2104)$ & $<0,001$ \\
\hline & Não & 21 & 6 & 27 & - & - & - \\
\hline & Total & 34 & 9 & 43 & - & - & . \\
\hline \multirow{3}{*}{$\begin{array}{c}\text { Partilhar roupas íntimas } \\
\text { e toalha }\end{array}$} & Sim & 10 & 0 & 10 & 0,6279 & $(-0,7956 ;-0,4602)$ & $<0,001$ \\
\hline & Não & 27 & 6 & 33 & - & - & - \\
\hline & Total & 37 & 6 & 43 & - & - & - \\
\hline
\end{tabular}

*: observações não são discrepantes.

Em relação ao conhecimento sobre as consequências da infecção por HPV, também foi uma das variáveis mais alteradas pela ação educativa, pois o conhecimento prévio sobre a consequência do vírus antes da ação educativa limitava-se somente a correlacioná-lo com o câncer de colo uterino e com verrugas vaginais. Após a ação educativa a presença de outras doenças causadas pelo HPV foi descrita com associação estatística significante (Tabela 3), mostrando assim a eficácia da ação educativa.

A alteração do conhecimento sobre as consequências da infecção pelo HPV foi ampliada no que tange à presença de verrugas em outras regióes do corpo que não seja as genitais, bem como a existência e tipos de outras doenças associadas com significância estatística, como observado na (Tabela 3). 
Tabela 3. Conhecimento sobre as consequências da infecção por HPV antes e após ação educativa realizada na Cadeia Pública Feminina e teste de McNemar, com suas respectivas diferenças ( $\Delta$ ), intervalo de confiança de 95\% (IC95\%) e valores de $p$, Tangará da Serra, MT, 2016

\begin{tabular}{|c|c|c|c|c|c|c|c|}
\hline \multirow{2}{*}{ Variável } & \multirow{2}{*}{ Pré } & Pós & & \multirow{2}{*}{ Total } & \multirow{2}{*}{$\Delta$} & \multirow{2}{*}{ IC95\% } & \multirow{2}{*}{$P$} \\
\hline & & Sim & Não & & & & \\
\hline \multirow{3}{*}{$\begin{array}{l}\text { Relação do HPV com o } \\
\text { câncer de colo de útero }\end{array}$} & Sim & 29 & 0 & 29 & *** & $* *$ & *** \\
\hline & Não & 22 & 0 & 22 & - & - & - \\
\hline & Total & 51 & 0 & 51 & - & - & - \\
\hline \multirow{3}{*}{$\begin{array}{l}\text { Relação das verrugas } \\
\text { vaginais e HPV }\end{array}$} & Sim & 25 & 0 & 25 & *** & $* *$ & ** \\
\hline & Não & 27 & 0 & 27 & - & - & - \\
\hline & Total & 52 & 0 & 52 & - & - & - \\
\hline \multirow{3}{*}{$\begin{array}{c}\text { Relação do HPV com ver- } \\
\text { rugas em outras regióes } \\
\text { do corpo }\end{array}$} & Sim & 21 & 1 & 22 & $-0,5000$ & $(-0,6693 ;-0,3307)$ & $<0,001$ \\
\hline & Não & 26 & 2 & 28 & - & - & - \\
\hline & Total & 47 & 3 & 50 & - & - & - \\
\hline \multirow{3}{*}{$\begin{array}{c}\text { Existência de outras } \\
\text { doenças causadas pelo } \\
\text { HPV }\end{array}$} & Sim & 20 & 1 & 21 & $-0,4510$ & $(-0,6176 ;-0,2844)$ & $<0,001$ \\
\hline & Não & 24 & 6 & 30 & - & - & - \\
\hline & Total & 44 & 7 & 51 & - & - & - \\
\hline \multirow{3}{*}{$\begin{array}{c}\text { Especificação de outras } \\
\text { doenças causadas pelo } \\
\text { HPV }\end{array}$} & Sim & 4 & 2 & 6 & $-0,3585$ & $(-0,5261 ;-0,1908)$ & $<0,001$ \\
\hline & Não & 21 & 26 & 47 & - & - & - \\
\hline & Total & 25 & 28 & 53 & - & - & - \\
\hline
\end{tabular}

*: observações não são discrepantes.

Observa-se a partir da (Tabela 4) que houve mudança significativa no conhecimento das reeducandas em relação às formas de cura do HPV após a ação educativa, mostrando que a ação teve influência positiva sobre essas reeducandas, pode-se observar ainda nessa tabela que as formas de tratamento já eram conhecidas, porém o conhecimento sobre o uso do preservativo não é alterado demonstrando que a finalidade do mesmo é discutida em diferentes cenários da vida, entre familiares, amigos, escola e mídia. 
Tabela 4. Conhecimento sobre tratamento, cura e prevenção do HPV antes e após ação educativa realizada na Cadeia Pública Feminina e teste de McNemar, com suas respectivas diferenças $(\Delta)$, intervalo de confiança de 95\% (IC95\%) e valores de $p$, Tangará da Serra, MT, 2016

\begin{tabular}{|c|c|c|c|c|c|c|c|}
\hline \multirow{2}{*}{ Variável } & \multirow{2}{*}{ Pré } & \multicolumn{2}{|l|}{ Pós } & \multirow{2}{*}{ Total } & \multirow{2}{*}{$\Delta$} & \multirow{2}{*}{ IC95\% } & \multirow{2}{*}{$P$} \\
\hline & & Sim & Não & & & & \\
\hline \multirow{3}{*}{ Tratamento químico } & Sim & 4 & 9 & 13 & 0,0710 & $(-0,2430 ; 0,3860)$ & 0,804 \\
\hline & Não & 7 & 8 & 15 & . & . & . \\
\hline & Total & 11 & 17 & 28 & - & - & - \\
\hline \multirow{3}{*}{ Tratamento cirúrgico } & Sim & 6 & 7 & 13 & 0,071 & $(-0,2050 ; 0,3480)$ & 0,778 \\
\hline & Não & 5 & 10 & 15 & - & - & - \\
\hline & Total & 11 & 17 & 28 & - & - & - \\
\hline \multirow{3}{*}{$\begin{array}{c}\text { Tratamento imuno- } \\
\text { lógico }\end{array}$} & Sim & 6 & 4 & 10 & $-0,071$ & $(-0,3270 ; 0,1840)$ & 0,754 \\
\hline & Não & 6 & 12 & 18 & - & - & - \\
\hline & Total & 12 & 16 & 28 & - & - & - \\
\hline \multirow{3}{*}{ Cura espontânea } & Sim & 0 & 1 & 1 & $-0,571$ & $(-0,8150 ;-0,3270)$ & 0,001 \\
\hline & Não & 17 & 10 & 27 & - & - & - \\
\hline & Total & 17 & 11 & 28 & - & - & - \\
\hline \multirow{3}{*}{$\begin{array}{l}\text { Existência de cura } \\
\text { para o HPV }\end{array}$} & Sim & 21 & 20 & 41 & 0,3396 & $(0,1734 ; 0,5059)$ & $<0,001$ \\
\hline & Não & 2 & 10 & 12 & - & - & - \\
\hline & Total & 23 & 30 & 53 & - & - & \\
\hline \multirow{3}{*}{$\begin{array}{l}\text { Uso de preservativo } \\
\text { como prevenção }\end{array}$} & Sim & 34 & 7 & 41 & $-0,0566$ & $(-0,2272 ; 0,1140)$ & 0,629 \\
\hline & Não & 10 & 2 & 12 & - & - & $\cdot$ \\
\hline & Total & 44 & 9 & 53 & - & - & - \\
\hline
\end{tabular}

*: observações não são discrepantes.

\section{DISCUSSÕES}

O perfil das 53 reeducandas em estudo reflete as descrições já apontadas em outras pesquisas, ou seja, mulheres jovens (idade variou de 18 e 59 anos, com média 31,6 anos, e a faixa etária mais prevalente entre 18 a 31 anos), a raça/cor dominante a parda $(73,2 \%)$, baixo grau de escolaridade das mulheres com que predominou do ensino fundamental ${ }^{10-12}$.

As similaridades nas características sociodemográficas são mantidas em relação ao estado civil com predomínio de solteira (48\%), e mães, sendo que $60,3 \%$ possuem até três filhos; dentre as profissões prevaleceram ser "do lar \dona de casa" (38,2\%), seguida vendedora $(9,1 \%)$. A causa da reclusão mais presente foi o tráfico de drogas (55\%), seguido por homicídio $(12,7 \%)$ sendo que a maioria $(61,1 \%)$ foi detida pela primeira vez ${ }^{11,12}$.

A população privada de liberdade vive com o mínimo de dignidade, pois não são garantidos a ela seus primordiais direitos como o da saúde, pois as unidades prisionais não são vista por gestores de saúde como espaço para prevenção e promoção a saúde tornando-se um lugar de grande desafio no campo da saúde pública ${ }^{13}$. 
Universalidade, integralidade e equidade são os princípios básicos do Sistema Único da Saúde (SUS), porém para se sejam seguidos no cotidiano, faz-se necessário que sentimentos como de vingança, revolta ou até mesmo de punição contra as pessoas encarceradas seja abolido, onde muitas vezes o próprio agente penitenciário torna-se o "juiz" podendo facilitar ou dificultar o acesso dessa população à saúde, acabando por não observar que toda ação desenvolvida nesse ambiente atinge de maneira direta três frações da população sendo a própria pessoa reeducanda, os familiares e os funcionários das prisões $^{14,15}$. As ações educativas devem ter por finalidade a promoção à saúde, reduzindo possíveis agravos que cercam essa população ligado ao conhecimento que lhes faltam

O conhecimento prévio em relação ao vírus do HPV e suas ações sobre a saúde foi apontado por $58,5 \%$ das reeducandas, relacionado a conversas com familiares e atividades informativas da mídia, porém o conhecimento estava associado apenas a sua relação com o câncer de colo de útero e a necessidade de coleta do exame preventivo, sem maiores informações sobre os demais aspectos que envolvem o ciclo de transmissão, tratamento e demais formas de prevenção.

Em estudo de Osis, Duarte e Sousa ${ }^{16}$ destaca que mesmo a população tendo amplo acesso a informações sobre saúde através da mídia, essas informações são transmitidas de maneira inadequada e/ou superficial acabando por não incentivar a procura aos serviços de saúde para a prevenção e promoção da saúde. Por sua vez, as ações e orientações prestadas por profissionais da saúde ultrapassam essa superficialidade, pois o aspecto de maior relevância no ambiente do cárcere torna-se o conhecimento e entendimento das mulheres que ali se encontram sobre as questões de saúde ${ }^{17}$.

É possível observar o histórico sobre a identificação de situações importantes relacionadas ao conhecimento sobre o HPV. Em relação à história pessoal, as mulheres que relataram ter coletado CCO em algum momento da vida foi predominante $(84,9 \%)$, no entanto apenas 5,7\% tiveram história de verruga vaginal, 11,3\% descreveram lesão no útero em anos anteriores e 3,8\% relataram ter atualmente lesão no colo do útero sem tratamento.
As ações educativas são os meios de informações primordiais para que a população assemelhe e entenda os riscos relacionados à saúde principalmente ao comportamento sexual, pois a educação em saúde tem por objetivo disseminar a informação e assim instrumentalizar a população para que esteja atenta às ações de promoção e proteção da saúde ${ }^{18}$. Nesse contexto, o vínculo enfermeiro-cliente torna-se a chave principal para o desenvolvimento de atividade educativa. Esta relação entre o enfermeiro-cliente deverá estar permeada por um movimento contínuo de diálogo e troca de experiências, procurando assim meios de reduzir os tabus, mitos e preconceitos, mostrando para a população que saúde e educação não são desassociadas e sim vinculadas uma a outra. O educador tem o papel de estimular a população a conhecer as questóes de saúde para que assim a mesma possa ser ativa no processo de autocuidado ${ }^{19}$.

O baixo nível de escolaridade descrito entre as reeducandas da cadeia pública feminina corrobora com estudo de Osis; Duarte; Sousa16 que descreveu que a média escolar da população não atinge os oitos primeiros anos da alfabetização, corroborando com outras reflexões que acrescentam que o baixo nível escolar podem refletir diretamente nos hábitos de vida, na procura dos serviços de saúde e na procura de informações sobre questões de saúde ${ }^{3,20}$. Neste sentido, a cadeia pública torna-se um local de maior acessibilidade para transmitir essas informações através de ações educativas, pois o ambiente e as poucas atividades a serem realizadas no cotidiano prisional proporcionam maior atenção desse público para os problema relacionados à saúde, atraindo a atenção para questões já vivenciadas por elas ou por pessoas próximas ${ }^{17}$.

A necessidade de ações educativas em ambientes penitenciários também foi destaque em estudo realizado no Ceará. Nesse estudo, o autor aponta que existe superficialidade nos conhecimentos básicos para a prevenção da saúde nos respectivos ambientes ${ }^{17}$. Essa realidade vivida em vários lugares do Brasil mostra que existe a necessidade de implementação de ações educativas no cárcere.

O estudo de Souza et al. ${ }^{21}$ destacou que 56,3\% de reeducandos de Goiânia também apresentaram fragilidade em relação ao conhecimento das formas de infecção de doenças transmissíveis, já que metade dessa 
população aprisionada desconhecia que a contaminação da hepatite $B$ poderia ocorrer pelo contato com o sangue contaminado e pela via sexual. O desconhecimento sobre as diferentes vias de transmissão das IST está presente de modo uniforme na população em geral, possivelmente em consequência do destaque dado pela mídia para a transmissão sexual e em especial a via vaginal ${ }^{3}$. O desconhecimento sobre as formas de transmissão do HPV aqui descritos enfatizam ainda mais a necessidade de ações educativas nesse ambiente e a importância de levar esse conhecimento às mulheres reclusas.

A transmissão do vírus do HPV pode ocorrer pelo contato direto com a pele infectada ou com a secreção que contenha o vírus ativo, sendo através do contato oro-genital, podendo ocorrer através do sexo oral ou transmissão vertical da mãe para o filho no momento do parto normal, relação genital-genital (anus, pênis e vagina), manual-genital podendo incluir a autoinoculação ou manuseios das mãos nos órgãos do parceiro, beijo se houver lesões ou presença de verrugas na mucosa oral. Fômites também são descritos, porém é uma das maneiras mais raras e inclui o partilhamento de toalhas usadas e roupas íntimas sem higienização adequada ${ }^{1}$.

Para Ayres et al..$^{22}$, a fragilidade que acerca o conhecimento em relação à prevenção das ISTs, principalmente relacionado ao vírus do HPV, mostra a importância de levarmos a informação às mulheres, pois disseminação do conhecimento que aborde a prevenção, com ênfase as ações efetivas na redução do risco de infecção poderá minimizar a disseminação do vírus podendo assim haver maior controle da transmissão pelo comportamento sexual seguro e informado.

Condiloma acuminado são erupções na pele causadas pelos tipos de baixo risco oncológicos 6 e 11, geralmente, aparecem na região genital e próximo ao ânus em homens e mulheres, nos casos menos frequente na vagina, ânus ou colo do útero e em lugares mais raros como palmas das mãos, dedos, lábios e mucosa oral por meio do contato manual-genital ${ }^{1}$.

Sabe-se que o HPV causa as Lesões Precursoras do Câncer Cervicouterino (LPCCU) que são divididas em dois grupos, sendo lesão intraepitelial escamosa de baixo grau (LSIL) que corresponde a NIC I e a lesão intraepitelial escamosa de alto grau (HSIL) corresponde as NIC II e III, os cânceres de colo uterino invasor podem evoluir a partir de uma NIC, porém nem toda NIC evoluirá para uma doença invasora, mas toda neoplasia intraepitelial cervical deverá ser acompanhada e tratada ${ }^{3}$.

O vírus do HPV é o principal fator de desenvolvimento da doença, entretanto, não é o único, pois existem fatores como socioeconômico e ambiental, hábitos de vida, multiparidade, multiplicidade de parceiros sexuais, uso prolongado de contraceptivo, tabagismo e hábitos inadequados de higiene que podem favorecer o desenvolvimento de câncer de colo uterino ${ }^{23}$.

Anjos et al. ${ }^{20}$ apresentam a importância de levar informações sobre os fatores de risco à essa população, pois elas desconhecem as diversas formas que potencializam o vírus do HPV para o desenvolvimento do câncer cervical entre outras consequências que a infecção pode causar. O homossexualismo e o bissexualismo também são fatores de risco importantes, pois a grande maioria das mulheres acreditam que não há transmissão de IST entre gêneros ${ }^{20}$.

Uma das doenças abordadas nessa ação educativa foi a papilomatose respiratória recorrente (PRR), doença rara, porém pode levar a criança a óbito. Trata-se de um tumor benigno epitelial que afeta de forma mais frequente a laringe, podendo atingir todo o trato respiratório ocluindo a passagem de ar para os pulmões, a PRR é transmitida por meio do parto normal se a mãe estiver infectada pelo vírus ativo do HPV. A estimativa na população pediátrica é de 4,3 por 100.000 crianças com PRR, os tipos 6 e 11 são os responsáveis pelo desenvolvimento do PRR, sendo que o tipo 11 é o mais grave podendo levar a criança a necessitar de traqueotomia, já os tipos 16 e 18 são responsáveis pela transformação maligna do $\mathrm{PRR}^{24}$.

O câncer oral também deve ser destacado ao se falar de consequências do HPV, pois corresponde a $4 \%$ de todos os tipos de cânceres, e população feminina ocupa o décimo lugar com $2 \%$ dessas neoplasias malignas. Potencialmente em lesões orais malignas foi identificado o vírus do HPV, entretanto o uso do tabaco pode potencializar as ações de oncogênese do HPV ou imunossuprimir deixando o tecido susceptível ao vírus ${ }^{25}$.

Já o câncer na região retal é decorrente da carga viral elevada do vírus do HPV, sendo o tipo 16 mais comumente encontrado nessa neoplasia anal de baixo risco 
e os tipos 6 e 11 nos casos de alto risco, a transmissão do vírus do HPV ocorre pela relação anus-genital tendo maior incidência por meio da relação de homossexualis$\mathrm{mo}^{3}$.

A disseminação de doenças das mulheres para os homens devem ser considerada, uma vez que associação do HPV com o câncer de pênis é realidade, representando esse tipo de câncer $2 \%$ de todos os casos de câncer masculino, sendo mais frequente nas regiões Norte e Nordeste. Silva Jr. et al.26 detectaram que em homens brasileiros 15,7\% das infecções genitais por HPV-6 e HPV11 evoluíram para o condiloma e aproximadamente 1\% das infecções por HPV-16 progrediu para neoplasia intraepitelial peniana com um tempo médio de progressão de 25 meses.

A não alteração sobre o conhecimento das reclusas correlacionando o vírus do HPV com o câncer de colo uterino e verrugas gênitas, ocorreu pelo apropriamento prévio de informações, possivelmente disseminados pela mídia. Osis, Duarte e Sousa ${ }^{16}$ apontam a mídia como principal fonte de informação sobre as vacinas do HPV, e sua ação na redução das verrugas gênitas (condiloma acuminado) e o câncer do colo uterino, a prevenção é potencializada quando se tem acesso aos conteúdos informativos trazidos pela mídia, quando em sua grande maioria as matérias veiculadas pelos meios de comunicação em relação ao câncer está relacionada com a vacina do HPV e seus benefícios.

A realização de ações educativas nas cadeias ou penitenciárias tem por objetivo a melhoria da qualidade de vida dessas mulheres sobre tudo ampliar o conhecimento referentes a questões de saúde, tornando-se assim possível a reflexão e promoção do autocuidado a partir das informações que lhes foram passadas diminuindo os fatores de risco para possíveis futuros desenvolvimento do câncer cervical ou outras consequências causadas pelo vírus HPV, além da garantia do acesso à saúde ${ }^{20}$.

O Ministério da Saúde destaca que não há evidências sobre existência de tratamento, disponíveis que elimine ou altere o curso natural da infecção pelo vírus do HPV, a única forma comprovada segundo estudos é somente por meio da eliminação espontânea do sistema imunológico do hospedeiro, já suas possíveis complicações possuem tratamento químico, cirúrgico e pelo uso de estimuladores da imunidade, essas ações têm o objetivo de reduzir, remover ou destruir as lesões, verrugas ou cânceres proporcionadas pelo HPV ${ }^{1}$.

A ausência de alteração do conhecimento sobre tratamento das complicações causadas pelo HPV entre as reclusas pode decorrer da sua história pessoal, ou seja, o predomínio de experiências das mulheres com a coleta do CCO em algum momento da vida, pode ter possibilitado acesso às informações de forma individual nas consultas médica e de enfermagem ou ainda a partir de experiências, vivências e observações do cotidiano ${ }^{27}$.

A alteração do conhecimento sobre a existência de cura e cura espontânea para HPV após a ação educativa pode estar relacionado com o desconhecimento prévio dessa temática, já que a grande maioria das mulheres não acredita na possibilidade da cura do vírus e entende que o controle da doença dar-se-á por meio do exame Papanicolau ${ }^{22}$. Os mesmos autores destacaram que a maior prevalência de HPV se deu em mulheres solteiras, que consomem bebida alcoólica e possuem histórico de grande número de parceiros sexuais ao longo da vida, sendo importante identificar a prevalência de HPV de alto risco oncogênico para auxiliar na identificação de mulheres sob maior risco de evolução para lesão preneoplásica.

Segundo Nicolau et al. ${ }^{17}$, o uso de preservativos no sistema carcerário tornou-se algo substancial. No Brasil, a prática de relação sexual desprotegida é um fator de risco para transmissão de IST mais significativo. No mesmo estudo percebeu que quando questionadas sobre a principal finalidade do preservativo masculino apenas $2 \%$ das mulheres não sabiam, porém quando questionadas em relação ao preservativo feminino o número se mostrou dez vezes maior do que o anterior, porém mesmo sabendo sua finalidade $29 \%$ das mulheres afirmam não utilizá-lo em relações homossexuais. Nogueira et al. ${ }^{28}$ apontaram que apenas 32,5\% de usuários de um centro de testagem e aconselhamento utilizam preservativo com parceiros fixos, demonstrando a baixa adesão em relacionamentos estáveis.

As ações educativas sobre prevenção levarão conhecimento não somente em relação à prevenção contra o vírus do HPV, mas de todas as outras possíveis IST, sendo então um instrumento essencial de promoção da saúde $^{19}$. As medidas preventivas mais importantes são o 
uso de preservativo, seja masculino ou feminino, além de evitar múltiplos parceiros sexuais, realizar a higiene pessoal e imunização ${ }^{1}$.

Diante do exposto é notória a necessidade de intervenções de cunho educativo nos cárceres para promover saúde e prevenir doenças, por meio da adoção de medidas de redução dos fatores de risco que predispõem os sujeitos à infecção por HPV, o que pode reduzir a vulnerabilidade desses indivíduos.

\section{CONCLUSÃO}

Houve implemento significativo no conhecimento dessas mulheres sobre o HPV após a intervenção proposta, principalmente em relação ao acesso da informação na prisão, transmissão pelo beijo, sexo oral e compartilhamento de roupas íntimas, além do conhecimento referente à relação do HPV com as verrugas, existências de outras doenças além do câncer de colo do útero, cura espontânea e existência de cura, todos com significância estatística $(p<0,001)$. Pode-se então perceber claramente o quanto as ações educativas são formas eficientes de informação que instrumentalizam as mulheres na tomada de decisão quanto à melhoria de sua qualidade de vida, seja por ações preventivas, sejam por reflexões que posteriormente possam ser difundidas para as pessoas com quem convivem.

Em se tratando de mulheres aprisionadas, estas informações são primordiais para redução das vulnerabilidades a que estão expostas, devendo assim ser estimuladas e inseridas nos cotidianos das prisões brasileiras. Entende-se como fragilidade do estudo a forma de condução pontual, sendo necessária a realização de novas abordagens similares que ampliem as possibilidades de discutir as ações educativas em saúde nos ambientes carcerários.

\section{REFERÊNCIAS}

Ministério da Saúde (BR). Guia Prático Sobre o HPV Perguntas e Respostas para profissionais da saúde. Brasília (DF): Ministério da Saúde; [internet] 2014 [acesso em 2017 jun 10]. Disponível em: http://portalarquivos.saude.gov.br/images/pdf/2014/marco/07/guia-perguntasrepostas-MS-HPV-profissionais-saude2.pdf
Zardo GP, Farah FP, Mendes FG, Franco CAGS, Molina GVM, Melo GN, et al. Vacina Como agente de imunização contra o HPV. Ciênc Saúde Colet. [internet] 2014 [acesso em 2017 Jun 16];19(9): 3799-3808. Disponível em: http:// www.scielo.br/pdf/csc/v19n9/1413-8123-csc-19-09-3799. pdf

Instituto Nacional de Câncer José Alencar Gomes da Silva. Incidência, mortalidade e morbidade hospitalar por câncer em crianças, adolescentes e adultos jovens no Brasil: informações dos registros de câncer e do sistema de mortalidade. Rio de Janeiro (RJ); 2016.

Fernandes RAQ, Narchi NZ. Enfermagem e saúde da mulher. Barueri(SP): Manole; 2007.

Ministério da Justiça (BR). Levantamento Nacional de Informações Penitenciárias - INFOPEN. Brasília (DF): Ministério da Justiça; [internet] 2014 [acesso em 2017 Maio 04]. Disponível em: http://www.justica.gov.br/noticias/ estudo-traca-perfil-da-populacao-penitenciaria-femininano-brasil/relatorio-infopen-mulheres.pdf

Silva EF, Ribeiro ER. Atenção à saúde da mulher em situação prisional. Rev Saúde e Desenvol. [internet] 2013[acesso em 2017 Mai 13];2(4):161-72. Disponível em: https://www.uninter.com/revistasaude/index.php/ saudeDesenvolvimento/article/viewFile/188/196

Luchesi LB, Santos CB. Enfermagem: o que esta profissão significa para adolescentes. Uma primeira abordagem. Rev Latinoam Enf. [internet] 2005[acesso em 2017 Jun 11];13(2):158-64. Disponível em: http://dx.doi. org/10.1590/S0104-11692005000200005

Instituto Brasileiro de Geografia e Estatística (IBGE). IBGE cidades: Tangará da Serra. Rio de Janeiro (RJ); [internet] 2017[acesso em 2017 Jun 16]. Disponível em: http://cidades.ibge.gov.br/xtras/perfil.php?lang $=$ \&codmun $=510795 \&$ search $=$ mato-grosso $\mid$ tangara-da-serra|infograficos:-informacoes-completas

Siegel, S.; Castellan, J. Estatística não-paramétrica para as Ciências do Comportamento. 2. ed. Penso; 2006.

Agnolo CMD, Belentani LM, Jardim APS, Carvalho MDB, Pelloso SM. Perfil de mulheres privadas de liberdade no interior do Paraná. Rev baiana saúde pública. [internet] 2013 [acesso em 2017 Mai 12];37(4):820-34. Disponível 
em: http://files.bvs.br/upload/S/0100-0233/2013/v37n4/ a4480.pdf

Ferrari IF, Machado MNM. Perfis de mães reeducandas convivendo com seus filhos. Pesqui prát Psicossociais. [internet] 2014 [acesso em 2017 Jun 1];9(2):173-83. Disponível em: http://www.seer.ufsj.edu.br/index.php/ revista_ppp/article/view/923/682

Berquó ES, Cavenaghi SM. Tendências dos diferenciais educacionais e econômicos da fecundidade no Brasil entre 2000 e 2010. In: XIX Encontro Nacional de Estudos Populacionais. São Paulo (SP); [internet] 2014 [acesso em 2017 Jun 26]. Disponível em: http://www.abep.org. br/publicacoes/index.php/anais/article/view/2189/2144

Soares Filho MM, Bueno PMMG. Demografia, vulnerabilidades e direito à saúde da população prisional brasileira. Ciênc Saúde Colet. [internet] 2016[acesso em 2017 Jun 05];21(7):1999-2010. Disponível em: http:// www.scielo.br/pdf/csc/v21n7/1413-8123-csc-21-07-1999. pdf

Instituto de Pesquisa Econômica Aplicada (IPEA). Texto para discussão/Instituto de Pesquisa Econômica Aplicada. [internet] 2015 [acesso em 2017 Jun 16]. Disponível em: http://repositorio.ipea.gov.br/bitstream/11058/4375/1/ td_2095.pdf

Rudnicki D, Schafer G, Silva JC. As máculas da prisão: estigma e discriminação das agentes penitenciárias. Rev direito GV. [internet] 2017 [acesso em 2017 Jul 3];13(2):608-27. Disponível em: http://www.scielo. $\mathrm{br} /$ scielo.php?script $=$ sci_arttext $\&$ pid $=S 1808$ 24322017000200608\&lng $=\overline{\text { en\& }}$ nrm $=$ iso

Osis MJD, Duarte GA, Sousa MH. Conhecimento e atitude de usuários do SUS sobre o HPV e as vacinas disponíveis no Brasil. Rev Saúde Pública. [internet] 2014 [acesso em 2017 Mai 4];48(1):123-33. Disponível em: http://www. scielo.br/pdf/rsp/v48n1/0034-8910-rsp-48-01-0123.pdf

Nicolau AIO, Ribeiro SG, Lessa PRA, Monte AS, Bernardo EBR, et al. Conhecimento, atitude e prática do uso de preservativos por presidiárias: prevenção das DST/HIV no cenário prisional. Rev Esc Enferm USP. [internet] 2012 [acesso em 2017 Jun 1];45(6):711-19. Disponível em: http://www.scielo.br/pdf/reeusp/v46n3/25.pdf

Mallamann DG, Galindo Neto NM, Sousa JC, Vasconcelos EMR. Health education as the main alternative to promote the health of the elderly. Ciênc Saude Colet. [internet] 2015 [acesso em 2017 Jun 22];20(6):1763-72. Disponível em: $\quad$ http://www.scielo.br/scielo.php?pid $=$ S1413$81232015000601763 \&$ script $=$ sci_arttext\&tlng $=$ en

Amaral MS, Gonçalves AG, Silveira LCG. Prevenção do câncer de colo de útero: a atuação do profissional enfermeiro nas unidades básicas de saúde. Rev Cient FacMais. [internet] 2017 [acesso em 2017 Jul 30];VIII(1):197-223.Disponívelem:http://revistacientifica. facmais.com.br/wp-content/uploads/2017/04/8PREVEN\%C3\%87\%C3\%830-DO-C\%C3\%82NCER-DECOLO-DE-\%C3\%9ATERO-A-ATUA\%C3\%87\%C3\%83ODO-PROFISSIONAL-ENFERMEIRO-NAS-UNIDADESB\%C3\%81SICAS-DE-SA\%C3\%9ADE.pdf

Anjos SJSB, Ribeiro SG, Lessa PRA, Nicolau AIO, Vasconcelos CTM Pinheiro AKB. Fatores de risco para o câncer de colo do útero em mulheres reclusas. Rev Bras Enferm. [internet] 2013 [acesso em 2017 Jul 15]:66(4):508-13. Disponível em: http://www.scielo.br/ pdf/reben/v66n4/v66n4a07.pdf

Sousa AO, Pereira GS, Souza GE, Teles SA. Avaliação do conhecimento, comportamentos de risco e adesão à vacina contra hepatite $\mathrm{b}$ em reeducandos da cidade de Goiânia, GO. Ciênc Cuidado Saúde Maringá. [internet] 2005 [acesso em 2017 Mai 25];4(3):250-58. Disponível em: http://periodicos.uem.br/ojs/index.php/ CiencCuidSaude/article/view/5204

Ayres ARG, Silva GA, Teixeira MTB, Duque KD, Machado MLSM, Gamarra CJ et al. Infecção por HPV em mulheres atendidas pela Estratégia Saúde da Família. Rev Saúde Publica. [internet] 2017 [acesso em 2017 Jul 8];51(92):1-11. Disponível em: http://www.rsp.fsp. usp.br/wp-content/uploads/articles_xml/0034-8910rsp-S1518-87872017051000065/0034-8910-rsp-S151887872017051000065-pt.x83902.pdf

Barasuol MEC, Schmidt DB. Neoplasia do colo do útero e seus fatores de risco: revisão integrativa. Rev Saúde e Desenvol. [internet] 2014 [acesso em 2017 Jun 16];6(3):139-53. Disponível em: https://www.uninter. 